\title{
Adolescent Boys are at Risk for Body Image Dissatisfaction and Muscle Dysmorphia
}

\author{
Karen M. Skemp ${ }^{1}$, Renae L. Elwood ${ }^{2}$, and David M. Reineke ${ }^{3}$ \\ ${ }^{1}$ Department of Health Education Health Promotion, University Wisconsin-La Crosse \\ ${ }^{2}$ Clinical Mental Health \& Addiction Counseling, Counselor Education Department \\ ${ }^{3}$ Department of Mathematics and Statistics, University Wisconsin-La Crosse
}

\begin{abstract}
Background and Purpose: Muscle Dysmorphia (MD) is characterized by extreme body dissatisfaction and a drive for muscularity that leads to compulsive behaviors to attain an ideal body shape. The primary purpose of this study was to assess the level of body image dissatisfaction (BID) among male adolescents $\left(\mathrm{N}=149\right.$, mean age $=15.01 \pm 1.85 \mathrm{y}$ and mean $\left.\mathrm{BMI}=23.26 \pm 5.01 \mathrm{~kg} / \mathrm{m}^{2}\right)$ and whether or not BID was correlated with behaviors associated with MD. A secondary purpose was to examine if a difference exists between athletes and non-athletes. Methods: The Eating Attitude Survey (EAS) was used to assess attitudes toward body weight and shape while the Muscle Dysmorphia Inventory (MDI) was used to assess the behavioral and psychological characteristics of MD. Results: This sample of male adolescents indicate some level of BID, which is also associated with overall higher scores for all subscales of the MDI, but especially the subscales relating to muscularity. Athletes in particular showed higher levels of BID and higher scores on the MDI. Conclusion: Individuals who work with adolescent boys should be aware that they can develop body dissatisfaction and may participate in compensatory behaviors that may be harmful to their overall health and development.
\end{abstract}

(C) 2019 Californian Journal of Health Promotion. All rights reserved.

Keywords: Muscle dysmorphia, body image, adolescent boys, drive for muscularity

\section{Introduction}

There is a plethora of research focusing on body dissatisfaction and eating behaviors among young women indicating adolescence as a time in which negative body image increases, as well as compensatory weight loss practices (Calzo et al., 2012; Lowe et al., 2019; Murray, Rieger, \& Byrne, 2018). More recently, it has been determined that adolescent boys also experience body dissatisfaction. Studies indicate that for boys, body dissatisfaction can stem from a perception of being "too fat, or "too thin" and therefore, their compensatory behaviors for modifying their body weight and shape may be different than those of girls. Thus, as opposed to solely pursuing a drive for thinness (generally indicated with the female adolescents), boys also show a drive for muscularity (McCabe \& Ricciardelli, 2004; Jones \& Crawford, 2005).
Like a drive for thinness, a drive for muscularity can lead to positive and/or negative health practices. Conscientiousness of dietary behaviors and exercise participation can be healthy, but when taken to extremes, some individuals may become pathologically obsessed and adopt unhealthy behaviors in pursuit of an ideal body weight or shape. Grieve (2007) found that the internalization of the muscular ideal appears to be very salient for early adolescents. Smolak, Murnen, and Thompson (2005) determined that approximately $25 \%$ of middle-school-age boys regularly lift weights to gain muscle mass. Whereas sport participation can be a very positive behavior, it has been determined that the type of sport that an individual participates in can lead to unhealthy practices. For example, sports that focus on 
weight, such as wrestling and cross-country running, can lead to unhealthy weight loss practices and eating disorders (Carl, Johnson, \& Martin, 2017). Similarly, sports that focus on muscle mass, such as football and weight lifting, may encourage the use of muscle building supplements and steroid abuse (Irving, Wall, Neumark-Sztainer, \& Story, 2002; Carl, Johnson, \& Martin, 2017). Retrospective reports of men with muscle dysmorphia (MD) indicate that symptoms manifest as early as the middle teenage years, making this an important age group to study. Overall, MD has been theorized to have an average age of onset of 19.4 years (Leone et al., 2015).

Muscle Dysmorphia (MD) is a form of Body Dysmorphic Disorder originally defined as an intense and excessive preoccupation or dissatisfaction with body size and muscularity (Pope, Gruber, Choi, Olivardia, \& Phillips, 1997). According to Rhea, Lantz, and Cornelius (2004), individuals with MD exhibit specific behavioral and psychological characteristics that can be divided into 2 categories: nutritional aspects and physique concerns. The nutritional component includes behaviors associated with dietary practices/eating habits, nutritional supplement use to enhance performance, and pharmacological use to increase muscular size and strength. Physique concerns are characterized by preoccupation with the size of one's body (referred to as body-size symmetry), concerns with hiding defects of one's body (referred to as physique protection), and exercise dependence. This conceptual model argues that individuals with $\mathrm{MD}$ are more likely to experience dissatisfaction with their physique, use bulky clothing, alter training times to hide their physique, and exercise compulsively to develop a hyper-mesomorphic physique. Specific symptoms of MD within adolescent samples have included body image disturbances, feelings of distress, excessive weight lifting, special diets, avoidance of situations in which the body is exposed, exercise or food regimens that cannot be controlled, persistent mirror checking and substance use (McCabe \& Ricciardelli 2004; Cafri, van den Berg, \& Thompson, 2006).

\section{The Current Study}

Current literature supports that during adolescence, boys are about equally divided between wanting to lose weight and wanting to increase weight (McCabe \& Ricciardelli, 2004; Jones \& Crawford, 2005). Few studies have discerned that wanting to gain weight means a "desire for increased muscle size." Therefore, the purpose of this study was to try to examine the level of body dissatisfaction among a group of adolescent males, and to further attempt to identify whether a negative body image results in a drive to lose weight or a drive to gain muscle. A secondary purpose of this study was to determine if there were any differences in body image and compensatory behaviors between male adolescent athletes and nonathletes.

\section{Participants}

\section{Methods}

Participants included male adolescents ages 1118 years of age $(\mathrm{N}=149$, mean age $=15.01 \pm$ $1.85 \mathrm{y}$ and mean BMI $=23.26 \pm 5.01 \mathrm{~kg} / \mathrm{m}^{2}$ ) and were recruited from local public and private elementary, middle, and high schools from the Midwest area. Approval from the La Crosse School Board and participating school administrators was obtained prior to participant recruitment. Parental consent was then collected from participating schools, which generated the sample of 149 participants. Participants were identified as athletes by answering yes to the following question: Are you involved in school athletics? $(\mathrm{N}=98)$ Age groups were separated into 11 to 13 years old $(\mathrm{N}=33), 14$ to 16 years old $(\mathrm{N}=83)$ and 17 to 18 years old $(\mathrm{N}=33)$.

\section{Procedures}

The Eating Attitude Survey (EAS) was used to assess attitudes toward body weight and shape, as well as eating and weight control practices (Moore, 1990). The EAS contains 16 "yes" or "no" questions. Additionally participants were allowed to volunteer information such as the amount of desired weight loss/gain, desired body part change, and frequency of eating behaviors. The EAS has been used in previous clinical research (Moore, 1988; 1990). The Muscle Dysmorphia Inventory (MDI) was used to further assess body image perceptions and 
identify the characteristics of muscle dysmorphia. This survey has been validated in previous research (Rhea, Lantz, \& Cornelius, 2004) and is a 27-item self-report measure designed for the assessment of behavioral and psychological characteristics associated with MD. The MDI contains six subscales (dietary behavior, supplement use, physique protection, exercise dependence, body size/symmetry, and pharmacological use) and each subscale uses a 6-point Likert scale ranging from "never" $(=1)$ to "always" (=6). All survey samples were collected in person by a research assistant and anonymity was assured to participants and parents. Height and weight were self-reported by the participants and BMIs were determined using the CDC's BMI for age calculations. Participants completed the surveys only after obtaining school administrator's approval as well as parental consent. Informed consent was also collected. All procedures were approved by the University of Wisconsin-La Crosse's Institutional Review Board for the protection of human subjects.

\section{Statistical Analyses}

Statistical analysis procedures included MANOVA, to compare population means among multiple subscales and chi-square or Fisher exact tests, to determine if associations existed among categorical variables. All data conditions for these procedures were examined and deemed satisfactory. A 5\% level of significance was used for each individual test. Each subscale score from the MDI for this study was calculated by summing all item scores for the subscale. Higher scores were associated with MD behaviors and potential risk for MD. Independent t-tests were used to test for differences in the population means among subscales at a .05 level of significance. Based on previous research, it is recommended that the subscales be totaled separately because each subscale is intended to measure a conceptually independent trait of MD (Lantz, Rhea, \& Cornelius 2002, Rhea Lantz, \& Cornelius 2004). Summing across subscale scores, therefore, could lead to misinterpretation of results. All statistical procedures were implemented with IBM SPSS Statistics version 22.0 (IBM Corp, 2013).

\section{Results}

Four percent of the participants were classified as "underweight," $58.4 \%$ of the participants were classified as a "healthy" weight, $15.4 \%$ were classified as "overweight" and $22.1 \%$ were classified as "obese." A Fisher exact test for association showed a significant difference in the percentages of adolescent males who were dissatisfied with their body weight among the BMI categories (Figure 1, $p=0.002$ ), with obese males having a significantly higher proportion who were dissatisfied with body weight than healthy males. The comparison of percentages of adolescent males who were dissatisfied with their body shape among the BMI categories showed a similar pattern as what was observed for dissatisfaction with weight, but the association was not statistically significant (Figure 2, $p=0.126$ ). There was a notable increase in the percent dissatisfied with body weight in the overweight and obese categories; however, $17.2 \%$ of males with a healthy BMI were also dissatisfied with their body weight. In regards to body shape, $24.1 \%$ of the males in the healthy BMI category were dissatisfied. As with body weight, there was a notable increase in body dissatisfaction with body shape among the adolescent males in the overweight (30.4\%) and obese categories (45.5\%). 
Figure 1.

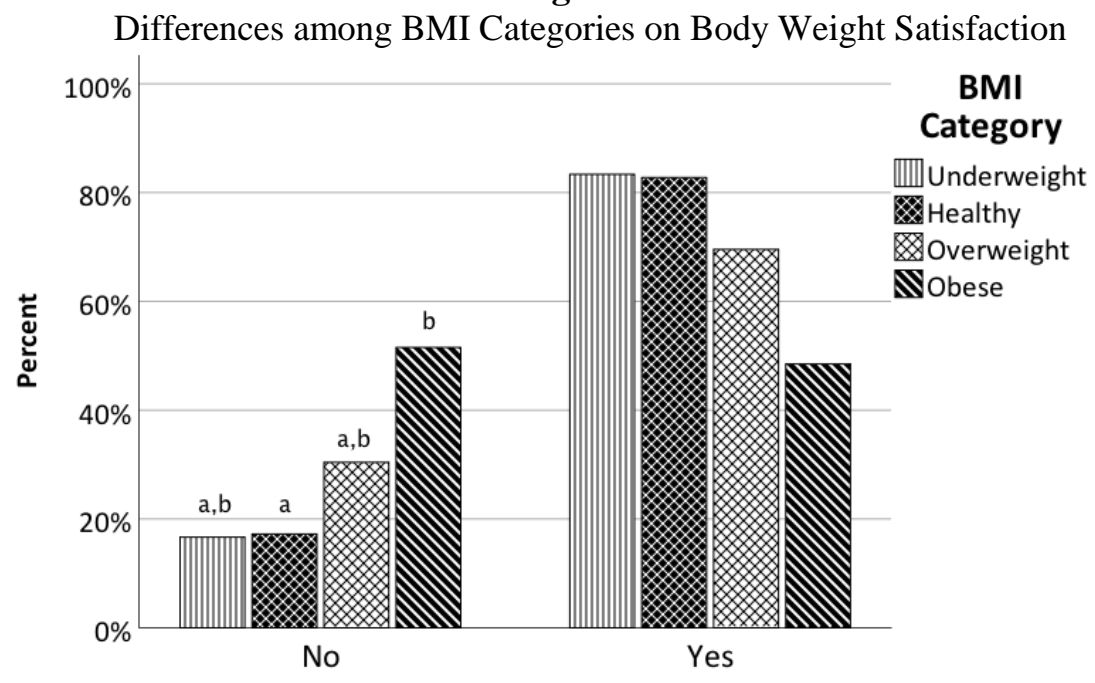

Are you satisfied with your body weight?

Note. The proportions for bars with the same letter are not significantly different.

Figure 2.

Differences among BMI Categories on Body Shape Satisfaction

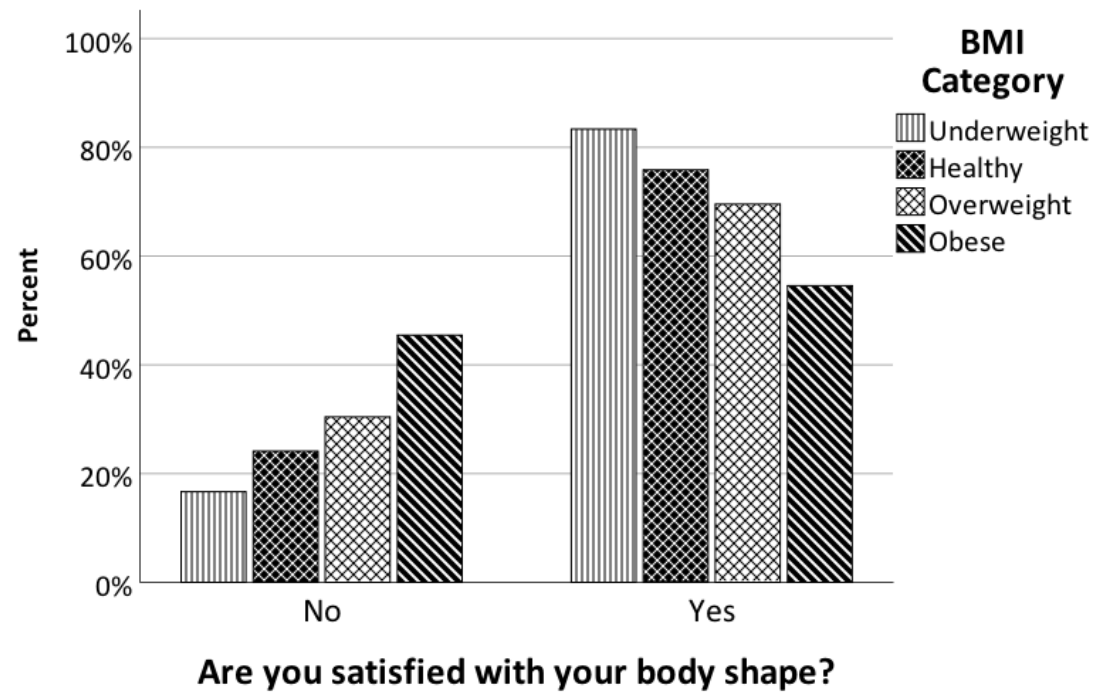

Overall, individuals who were dissatisfied with their weight (26.8\%) scored significantly higher on both Physique Protection (Mean $=14.36 \pm$ 5.5 vs. $11.62 \pm 5.2, p=0.012$, Hedges' $\mathrm{g}=0.52$ ) and Size/Symmetry $(15.42 \pm 6.1$ vs. $12.59+5.4$, $p=0.015$, Hedges' $g=0.51$ ) subscales than those who were satisfied with their weight.
Moreover, those who were dissatisfied with their body shape (29.5\%) also had significantly higher scores on the Size/Symmetry $(16.14 \pm 6.0$ vs. $12.01 \pm 5.1, p<0.0005$, Hedges' $g=0.76$ ) subscale than those who were satisfied with their body shape (Table 1). 
Table 1.

Body Dissatisfaction and Behaviors Associated with Muscle Dysmorphia

\begin{tabular}{lrrrr}
\hline & $\begin{array}{c}\text { Dissatisfied with } \\
\text { weight }\end{array}$ & $\begin{array}{c}\text { Satisfied with } \\
\text { weight }\end{array}$ & $\begin{array}{c}\text { Dissatisfied with } \\
\text { shape }\end{array}$ & $\begin{array}{c}\text { Satisfied with } \\
\text { shape }\end{array}$ \\
\hline Total Sample & $\mathrm{n}(\%)$ & $\mathrm{n}(\%)$ & $\mathrm{n}(\%)$ & $\mathrm{n}(\%)$ \\
Diet & $40(26.8)$ & $109(73.4)$ & $44(29.5)$ & $105(70.5)$ \\
Supplement & $10.92(4.5)$ & $11.01(4.7)$ & $11.58(5.0)$ & $10.71(4.4)$ \\
Physique Protection & $7.63(3.7)$ & $7.60(4.5)$ & $7.89(4.4)$ & $7.49(4.3)$ \\
Exercise Dependence & $14.36 *(5.5)$ & $11.62 *(5.2)$ & $13.47(6.0)$ & $11.83(5.1)$ \\
Size/Symmetry & $9.92(5.0)$ & $10.60(5.0)$ & $10.91(5.5)$ & $10.19(4.8)$ \\
Pharmacology & $15.42 *(6.1)$ & $12.59 *(5.4)$ & $16.14 *(6.0)$ & $12.07 *(5.1)$ \\
\hline
\end{tabular}

*Means of dissatisfied vs. satisfied are significantly different $(p<0.05)$.

Further results indicated that $29.6 \%$ of athletes $(\mathrm{N}=98)$ were dissatisfied with their body weight vs. $21.6 \%$ of non-athletes. Regarding body shape, $32.7 \%$ of athletes were dissatisfied vs. $23.5 \%$ of non-athletes (Table 2). When comparing athletes who were dissatisfied with weight to non-athletes who were dissatisfied with weight, there was a significant difference between scores on the MDI subscales of Supplement Use $(8.76 \pm 3.9$ vs. $5.18 \pm 1.9, p=$ 0.006, Hedges' $\mathrm{g}=1.03$ ) and Exercise Dependence $(10.40 \pm 4.7$ vs. $7.18 \pm 3.4, p=$ 0.048, Hedges' $\mathrm{g}=0.73$ ). For within group comparisons, athletes who were dissatisfied with their weight scored significantly higher on the
MDI subscales of Physique Protection (15.32 \pm 5.3 vs. $11.42 \pm 5.4, p=0.003$, Hedges' $g=0.73)$ and Size Symmetry (16.48 \pm 6.5 vs $13.45 \pm 5.2$, $p=0.037$, Hedges' $\mathrm{g}=0.54)$ than athletes who were satisfied with their weight. Athletes who were dissatisfied with their shape scored significantly higher on the Size Symmetry subscale than athletes who were satisfied with their shape $(16.76 \pm 5.8$ vs. $12.91 \pm 5.1, p=$ 0.003, Hedges' $g=0.72$ ). Similarly, nonathletes dissatisfied with their shape scored significantly higher on the Size Symmetry subscale than non-athletes who were satisfied with their shape $(14.92 \pm 6.7$ vs. $10.53 \pm 4.2, p=$ 0.011 , Hedges’ $g=0.90)$.

Table 2.

Body Dissatisfaction and Behaviors Mean (SD) among Athletes and Non-Athletes

\begin{tabular}{|c|c|c|c|c|c|}
\hline & & $\begin{array}{c}\text { Dissatisfied with } \\
\text { weight }\end{array}$ & $\begin{array}{c}\text { Satisfied with } \\
\text { weight }\end{array}$ & $\begin{array}{l}\text { Dissatisfied } \\
\text { with shape }\end{array}$ & $\begin{array}{l}\text { Satisfied with } \\
\text { shape }\end{array}$ \\
\hline \multirow[t]{7}{*}{ Athletes } & n (\%) & $29(29.6)$ & $69(70.4)$ & $32(32.7)$ & $66(67.3)$ \\
\hline & Diet & $11.60(4.6)$ & $11.58(4.6)$ & $12.07(4.3)$ & $11.34(4.7)$ \\
\hline & Supplement Use & $8.76^{\mathrm{b}}(3.9)$ & $7.70(4.8)$ & $8.59(4.2)$ & $7.71(4.7)$ \\
\hline & Physique Protection & $15.32^{\mathrm{a}}(5.3)$ & $11.42^{\mathrm{a}}(5.4)$ & $14.00(6.6)$ & $11.82(4.9)$ \\
\hline & Exercise Dependence & $10.40^{\mathrm{b}}(4.7)$ & 11.92 (4.9) & $11.48(4.5)$ & $11.46(5.0)$ \\
\hline & Size/Symmetry & $16.48^{\mathrm{a}}(6.5)$ & $13.45^{\mathrm{a}}(5.2)$ & $16.76^{\mathrm{a}}(5.8)$ & $12.91^{\mathrm{a}}(5.1)$ \\
\hline & Pharmacology & $3.48(2.4)$ & $3.05(0.4)$ & $3.00(0.0)$ & 3.27 (1.6) \\
\hline \multirow[t]{7}{*}{ Non-Athletes } & n (\%) & $11(21.6)$ & $40(78.4)$ & $12(23.5)$ & $39(76.5)$ \\
\hline & Diet & $9.45(3.8)$ & $10.08(4.8)$ & $9.75(6.4)$ & $10.00(3.9)$ \\
\hline & Supplement Use & $5.18^{\mathrm{ab}}(1.9)$ & $7.59^{\mathrm{a}}(4.7)$ & $6.17(4.8)$ & $7.33(4.2)$ \\
\hline & Physique Protection & $12.18(5.6)$ & $12.08(5.3)$ & $12.42(5.1)$ & $12.00(5.4)$ \\
\hline & Exercise Dependence & $7.18^{\mathrm{b}}(3.4)$ & $8.70(4.9)$ & $8.75(6.7)$ & $8.22(3.8)$ \\
\hline & Size/Symmetry & $12.82(4.5)$ & $11.27(5.5)$ & $14.92^{\mathrm{a}}(6.7)$ & $10.53^{\mathrm{a}}(4.2)$ \\
\hline & Pharmacology & $3.00(0.0)$ & $3.16(1.0)$ & $3.00(0.0)$ & 3.17 (1.0) \\
\hline
\end{tabular}

${ }^{\mathrm{a}}$ Means are significantly different $(p<0.05)$ dissatisfied vs. satisfied within athlete/non-athlete groups.

${ }^{\mathrm{b}}$ Means are significantly different $(p<0.05)$ athlete vs. non-athlete. 


\section{Discussion}

This study indicates that some adolescent males exhibited body dissatisfaction followed by an interest in building muscle. This was assessed using follow-up questions to qualify why participants were "dissatisfied with their weight" which indicated that many participants thought they were "too fat" (70\% of these respondents). In regards to "dissatisfaction with body shape," $64 \%$ of these respondents wanted to "increase muscle;" in particular, comments involved "building chest, arms, and abs." These findings are similar to those by Moore (1990) in which he determined that boys dissatisfied with their body shape wanted "bigger arms and chest" and "decreased abdomen size." Similarly, in a study of 12 to 14-year-old boys, McCabe and Ricciardelli (2001) found that some boys wanted to "change the size or strength of the muscles...of the chest, shoulders, and stomach (p.230)." McCreary and Sasse (2010) used the Drive for Muscularity Scale (DMS) to assess body dissatisfaction and found that boys scored higher on the DMS and these higher scores were linked to boys wanting "larger pectorals, biceps, wrists, shoulders, forearms, and flatter abdominals (p. 301).” The current study further supports this connection with body dissatisfaction and an interest in muscularity such that those who were dissatisfied with weight and shape had overall higher scores for most of the subscales of the MDI. This was especially evident in the subscales relating to muscularity, such as Size Symmetry and Physique Protection. The Size Symmetry subscale includes the following questions: I am concerned with losing muscle mass; I am preoccupied that I look small; Developing large muscle mass is important to me; I will benefit from having large muscles; I am preoccupied with a desire to be larger. The Physique Protection subscale includes the following questions: I wear bulky clothing to hide my muscular physique from others; I prefer to work out when no one else can see me; I avoid situations where other weight lifters may see my muscle development; I wear clothes that help conceal the size of my physique; It is important that other weight trainers see how muscular I am; I would rather keep others from seeing my level of muscle development.

Another finding in the current study indicated that $24.1 \%$ of males with a healthy BMI were dissatisfied with their body shape and $60 \%$ of these respondents reported their reason for dissatisfaction was they felt they were "too thin." The current literature estimates that between 28 and $68 \%$ of normal weight adolescent boys want to or are already trying to gain weight. Moore (1990) also found that a larger percent of normal weight boys in his study indicated an interest in pursuing muscularity.

Calzo et al. (2012) measured body image perceptions of girls and boys ages 9-18 years old. Girls above the 50th BMI percentile reported greater body dissatisfaction than girls below the 50th percentile. By contrast, boys who reported the most body dissatisfaction were either above the 75th BMI percentile (approaching overweight) or below the 10th percentile (approaching underweight). Male and female participants in the overweight/obese BMI range reported the greatest weight concern. The current study found similar findings regarding BMI with the overweight/obese category with $43 \%$ of overweight and obese males reporting the highest dissatisfaction of body weight and $39 \%$ with body shape. This fact could account for higher scores in the Physique Protection subscales of the MDI among those dissatisfied with weight compared to those satisfied with weight. Other studies have shown similar behaviors in boys who want to change their body size or shape (McCabe and Ricciardelli, 2001).

Calzo et al.'s (2012) study also found that body dissatisfaction increased with age for both girls and boys. The current study, however, did not show the same trend with boys in the youngest age group indicating the highest levels of dissatisfaction with weight (36.4\%, 25.3\%, $21.2 \%$, respectively). In an early study by Rosenblum and Lewis (1999), boys showed an increase in body satisfaction between the ages of 13 to 15 . Similarly, the current study indicated that overall, boys in the age group of 14 to 16 
showed an increased level of satisfaction with weight $(74.7 \%)$ and the highest level of satisfaction with body shape (73.5\%). The oldest age category (17 to 18) also showed increased satisfaction with weight (78.8\%), but a decrease in satisfaction with body shape (63.6\%). This appears to be consistent with the current literature. Pubertal timing may play a strong role in boys' body image perceptions, especially in relation to the sociocultural body ideal of a more muscular build (McCabe \& Ricciardelli, 2004). Pubertal development in boys moves them closer to the societal "ideal" by increasing height and muscle mass while decreasing body fat and enhancing masculine features (e.g., body and facial hair) indicating maturity and masculinity. Boys who lag in pubertal development may feel inferior and experience greater body image dissatisfaction (Leone et al., 2015, McCabe \& Ricciardelli, 2004). The current study did not assess pubertal timing. Therefore, we can only surmise that the younger age group had not yet started maturing toward the sociocultural mesomorphic body ideal. This may account for their higher levels of body dissatisfaction in weight. The oldest age group may be showing greater interest in attaining that ideal shape, thus indicating higher levels of dissatisfaction specific to body shape.

Sport participation can be a positive experience for adolescents, but certain sports can contribute to negative outcomes such as unhealthy dieting practices and eating disorders (e.g. wrestling) or unhealthy muscle building techniques and the development of muscle dysmorphia (e.g. football). The current study explored the differences in overall body dissatisfaction between athletes and non-athletes, but further looked to determine if athletes showed greater characteristics of muscle dysmorphia. Results of the current study indicated that $29.6 \%$ of athletes ( $\mathrm{N}=98$ ) were dissatisfied with their body weight vs. $21.6 \%$ of non-athletes. Regarding body shape, $32.7 \%$ of athletes were dissatisfied vs. $23.5 \%$ of non-athletes. Athletes who were dissatisfied with weight and shape generally had higher scores on the MDI subscales especially those related to muscularity. When comparing athletes to the non-athletes, those who were dissatisfied with their weight had higher scores on the Supplement Use and Exercise Dependence subscales. This could indicate that athletes use different compensatory methods to change body weight compared to those who do not participate in athletics. Studies have determined that adolescent boys use different strategies to change their body weight, more specifically the use of exercise rather than changing their eating patterns (Moore, 1993; McCabe \& Ricciardelli, 2001). In the current study, the use of exercise may just be part of the nature of athletics and thus account for the higher scores of athletes vs. non-athletes. Regardless, maintaining a strict workout schedule, working out to develop the maximum amount of muscle mass, "being bothered" by missing a scheduled workout or having a difficult time taking a day off from working out were questions used to assess exercise dependence; hence, indicating a clear reliance on this method to manage or change body weight.

Another weight change strategy found in the literature among adolescents and young men is the use of steroids and drugs (Wroblewska, 1997; Irving, Wall, Neumark-Sztainer, \& Story, 2002; Cafri, van den Berg, \& Thompson, 2006; Neumark-Sztainer \& Eisenberg, 2014). In the current study, all groups scored low on the "Pharmacology" subscale; however, both athletes and non-athletes who indicated dissatisfaction with their weight scored higher on the "Supplement Use" subscale. The MDI measures supplement use with questions about the use of energy/pre-workout supplements, recovery/post-workout supplements, supplements to enhance weightlifting performance, and supplements to help train through injury. These questions do not include the use of supplements for weight loss, which could lend further support that male adolescents rely on exercise to change body weight, since all questions pertained to enhancing the ability to exercise, more specifically to enhance workouts.

Research indicates that sports emphasizing leanness, weight classes, strength and/or aesthetics are most susceptible to developing muscle dysmorphia symptoms (Grieve, 2007). Among participants in the current study, adolescent males were clearly showing 
dissatisfaction in weight and shape. Furthermore, compensatory methods in changing weight and shape are different from what the literature shows for adolescent girls, generally favoring a body shape that is more muscular and using exercise techniques in order to change their body weight and shape (Moore, 1993; McCabe \& Ricciardelli, 2001). The current study indicates that athletes tend to show greater dissatisfaction in weight and shape compared to non-athletes. Athletes also scored higher on most of the MDI subscales. This could indicate that the nature of athletics could potentially increase the risk for the development of muscle dysmorphia among adolescent boys.

\section{Limitations}

As indicated, the current study did not assess pubertal timing in this sample of adolescent boys. Pubertal development can potentially contribute to a variety of physiological and psychosocial processes. "If puberty is not considered...then erroneous conclusions might be made about health or developmental outcomes in adolescents" (Dorn, 2006, p. 625). Therefore, it is recommended that future studies include some measure of pubertal status or timing. Additionally, body dissatisfaction has been correlated with lower self-esteem and higher levels of depression, thus indicating that the pursuit of an "ideal" body weight or shape can affect adolescent boys in many ways (Rawana, Morgan, Nuguyen, \& Craig, 2010; Hoffmann, Cortes-Garcia, \& Warschburger,
2018; Murray, Rieger, \& Byrne, 2018). While not measured in this study, it is recommended that future studies consider screening for depression particularly in those who show higher body dissatisfaction. Lastly, future research should seek to determine if the trends found in the current study occur across all age groups, if there are differences among racial/ethnic groups, and at what age and in what sports these symptoms begin to manifest.

\section{Conclusion}

Individuals who work with adolescent boys would do well to be aware of the idea that boys can develop body dissatisfaction and may participate in compensatory behaviors that may be harmful to their overall health and development. Fostering positive body and selfesteem, awareness of potential maladaptive behaviors, and early intervention is critical. Coaches, educators, clinicians, and parents of adolescent boys should become well versed in the use of questioning techniques specific to identifying whether MD is present among their athletes, students, and patients they work with. They can then discuss the natural differences in body shapes and sizes, potentially dangerous practices in manipulating body shape or size, and offer healthier options for improving one's weight status and physical fitness (NeumarkSztainer \& Eisenberg, 2014). The reader is referred to the conceptual model of intervention presented by Leone, Sedory, and Gray (2005).

\section{References}

Cafri, G, van den Berg, P., \& Thompson, J.K. (2006). Pursuit of muscularity in adolescent boys: Relations among biopsychosocial variables and clinical outcomes. Journal of Clinical Child and Adolescent Psychology, 35(2), 283-91.

Calzo, J.P., Sonneville, K.R., Haines, J., Blood, E.A., Field, A.E. \& Austin, S.B. (2012). The development of associations among body mass index, body dissatisfaction, and weight and shape concern in adolescent boys and girls. Journal of Adolescent Health, 51, 517-23.

Carl, R.L, Johnson, M.D., \& Martin, T.J. (2017). Promotion of healthy weight-control practices in young athletes. Pediatrics, 140(3), 1-13. https://doi.org/10.1542/peds.2017-1871

Dorn, L.D. (2006). Measuring Puberty. Journal of Adolescent Health, 39(5), 625 - 626. https://doi.org/10.1016/j.jadohealth.2006.05.014

Grieve, F.G. (2007). A conceptual model of factors contributing to the development of muscle dysmorphia. Eating Disorders, 15, 63-80. 
Hoffmann, S., Cortes-Garcia, L., \& Warschburger, P. (2018). Weight/shape and muscularity concerns and emotional problems in adolescent boys and girls: A cross-lagged panel analysis. Journal of Adolescence, 68, 70-77. https://doi.org/10.1016/j.adolescence.2018.07.005

IBM Corp. Released 2013. IBM SPSS Statistics for Macintosh, Version 22.0. Armonk, NY: IBM Corp.

Irving, L.M., Wall, M., Neumark-Sztainer, D., \& Story, M. (2002). Steroid use among adolescents: Findings from the Project EAT. Journal of Adolescent Health, 30, 243-252.

Jones, D.C. and Crawford, J.K. (2005). Adolescent boys and body image: Weight and muscularity concerns as dual pathways to body dissatisfaction. Journal of Youth and Adolescence, 34(6), 629-636.

Lantz, C.D., Rhea, D.J., \& Cornelius, A.E. (2002). Muscle dysmorphia in elite-level power lifters and bodybuilders: A test of differences within a conceptual model. Journal of Strength \& Conditioning Research, 16, 649-655.

Leone J.E., Sedory E.J., \& Gray, K.A. (2005). Recognition and treatment of muscle dysmorphia and related body image disorders. Journal of Athletic Training 40(4), 352-359.

Leone J.E., Wise K.A., Mullin E.M., Harmon W., Moreno N., \& Drewniany J. (2015). The effects of pubertal timing and alexithymia on symptoms of muscle dysmorphia and the drive for muscularity in men. Psychology of Men \& Masculinity, 16(1), 67-77.

Lowe, M. R., Marmorstein, N., Iacono, W., Rosenbaum, D., Espel-Huynh, H., Muratore, A. F. . Zhang, F. (2019). Body concerns and BMI as predictors of disordered eating and body mass in girls: An 18-year longitudinal investigation. Journal of Abnormal Psychology, 128(1), 32-43.

http://dx.doi.org/10.1037/abn0000394

McCabe, M.P. \& Ricciardelli L.A. (2001). Parent, peer, and media influences on body image and strategies to both increase and decrease body size among adolescent boys and girls.

Adolescence, 36(142), 225-40.

McCabe, M.P. \& Ricciardelli L.A. (2004). Body image dissatisfaction among males across the lifespan: A review of past literature. Journal of Psychosomatic Research, 56, 675-85.

Mccreary, D.R. \& Sasse, D.K. (2010). An exploration of the drive for muscularity in adolescent boys and girls. Journal of American College Health 48, 297-304.

Moore, D.C. (1988). Body image and eating behavior in adolescent girls. American Journal of Diseases of Children, 142 (10):1114-1118. doi:10.1001/archpedi.1988.02150100108038

Moore, D.C. (1990). Body image and eating behavior in adolescent boys. American Journal of Diseases of Children, 144(4), 475-79. doi: 10.1001/archpedi.1990.02150280097020

Moore, D.C. (1993) Body image and eating behavior in adolescents. Journal of the American College of Nutrition, 12(5), 505-510. doi: 10.1080/07315724.1993.10718343

Murray, K., Rieger, E., \& Byrne, D. (2018). Body image predictors of depressive symptoms in adolescence. Journal of Adolescence, 69, 130-139.

Pope, H.G., Gruber, A.J., Choi, P., Olivardia, R., \& Phillips, K.A. (1997). Muscle dysmorphia: An underrecognized form of body dysmorphic disorder. Psychosomatics 38, 548-557.

Neumark-Sztainer, D. \& Eisenberg, M.E. (2014). Body image concerns, muscle-enhancing behaviors, and eating disorders in males. Journal of American Medical Association Pediatrics, 312(20), 21562157. doi:10.1001/jama.2014.5138

Rhea, D.J., Lantz, C.D., \& Cornelius, A.E. (2004). Development of the muscle dysmorphia inventory (MDI). The Journal of Sports Medicine and Physical Fitness, 44, 428-35.

Rosenblum, G.D. \& Lewis, M. (1999). The relations among body image, physical attractiveness and body mass in adolescence. Child Development, 70, 50-64.

Rawana, J.S., Morgan, A.S., Nuguyen, H., \& Craig, S.G. (2010). The relation between eating- and weight-related disturbances and depression in adolescence: A review. Clinical Child Family Psychology Review, 13 (3), 213-230. https://doi.org/10.1007/s10567-010-0072-1

Smolak, L., Murnen, S.K. \& Thompson, J.K. (2005). Sociocultural influences and muscle building in adolescent boys. Psychology of Men and Muscularity, 6, 227-239. 
Wroblewska, A. (1997). Androgenic-anabolic steroids and body dysmorphia in young men. Journal of Psychosomatic Research, 42, 225-234.

\author{
Author Information \\ Karen M. Skemp, Ph.D.* \\ Associate Professor \\ Department of Health Education Health Promotion \\ University Wisconsin-La Crosse \\ 1725 State Street \\ La Crosse, WI 54601 \\ kskemp@uwlax.edu \\ 608-785-8187 (phone) \\ 608-785-6792 (fax)
}

